\title{
Studies on Biology of Greater Wax Moth (Galleria mellonella L.)
}

\author{
Venkatesh Hosamani $^{1 *}$, B.C. Hanumantha Swamy $^{2}$, K.N. Kattimani ${ }^{1}$ and C.M. Kalibavi \\ ${ }^{1}$ College of Horticulture, Munirabad- Koppal 583233, Karnataka, India \\ ${ }^{2}$ Krishi Vigyan Kendra, UAHS, Shimoga, Karnataka, India \\ ${ }^{3}$ Extension Leader and Agronomist, AEEC, Huvinahadagali, UAS, Raichur, India \\ *Corresponding author
}

\begin{tabular}{|c|c|}
\hline & A B S T R A C T \\
\hline & nellonella revealed that the \\
\hline Keywords & incubation period was $8.80 \pm 0.48$ days. The seven successive larval instars \\
\hline $\begin{array}{l}\text { Biology, Greater wax } \\
\text { moth. }\end{array}$ & 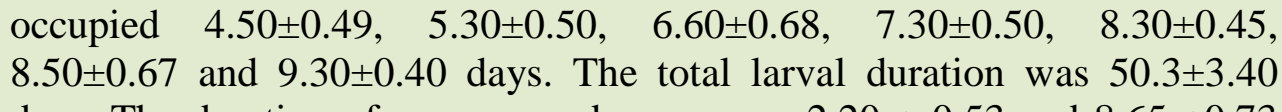 \\
\hline Article Info & $\begin{array}{l}\text { days. The duration of prepupa and pupa were } 2.20 \pm 0.53 \text { and } 8.65 \pm 0.73 \\
\text { days respectively. The adult males lived for } 16.50 \pm 2.70 \text { days, while female }\end{array}$ \\
\hline $\begin{array}{l}\text { Accepted: } \\
\text { 28 September } 2017 \\
\text { Available Online: } \\
10 \text { November } 2017\end{array}$ & $\begin{array}{l}\text { lived shorter only } 6.88 \pm 0.73 \text { days. Pre oviposition, Oviposition, Post- } \\
\text { oviposition periods for females were } 1.10 \pm 0.30,4.70 \pm 0.66 \text { and } 1.22 \pm 0.40 \\
\text { days, respectively. Females laid an average of } 760.9 \pm 168.88 \text { eggs } / \text { female } \\
\text { with } 161.80 \pm 45.87 \text { eggs/female/day }\end{array}$ \\
\hline
\end{tabular}

\section{Introduction}

Bee keeping has taken a shape of promising enterprise and also becoming popular as one of the components in Integrated farming systems. There is a great scope for increasing the bee colonies for honey and wax production and also for pollination services. Despite its prosperity, potentiality and wider scope for development, there are some built in problems in Indian bee keeping. One such major problem is the occurrence of various natural enemies, which cause considerable losses to bee keeping industry. The greater wax moth Galleria mellonella is considered as a notorious pest of honey bee colonies which is well distributed throughout the world. The wax moth larvae did not cause direct damage to Honeybees at any living stage, but they are very destructive to the combs. They eat the wax of the comb and other associated materials viz., pollen, propolis, dead bees and pupal cases of bees. The larvae of wax moth bore in to the combs and make tunnels in the middle of the comb. Later black excreta can also be noticed in the web. As a result of serious infestation, weak bee colonies abscond, while in strong colonies bee population quickly reduced and complete destruction of colonies have also been recorded (Hanumantha Swamy, 2000). It caused considerable damage to honey bee colonies which resulted in heavy economic losses to bee keepers (Kapil and Sihag, 1983). 
The information on the biology parameters of greater wax moth is little scanty. Hence, the present study was conducted to know the biological parameters of greater waxmoth

\section{Materials and Methods}

Present investigation has been carried out at college of horticulture, munirabad, koppal in department of entomology during 2014-15. Initial culture of greater wax moth was collected in Apis cerana colonies from different apiary and developed in the laboratory. The eggs from the laboratory culture were kept in separate containers and were observed at $24 \mathrm{hr}$ interval and the incubation period was recorded. Length and breadth of eggs were also measured by using a stereo binocular microscope with ocular micrometer fixed at one eye piece. After hatching, the observations were made regularly for moulting, the number of moults and instars passed during the larval development. Larval, Prepupal, pupal durations, length and breadth were also measured. After adult emergence pair of male and female moths was released separately in to wide mouthed plastic containers for egg laying. The paper strips were removed once in 24 hours and numbers of eggs, if any, were counted under stereo binocular microscope and later paper strips were kept in plastic vials for incubation. Pre oviposition, oviposition and post oviposition periods were recorded, simultaneously. Fecundity and eggs per day were calculated for female

\section{Results and Discussion}

\section{Egg}

Eggs of wax moth are very small, elliptical and whitish in colour when laid but they turns creamy colour when they are exposed to air. The eggshell having much number of wavy lines running across it diagonally. Eggs were laid in groups, glued to the inner side of the paper strips provided for egg laying under laboratory conditions, but some time few eggs are also laid in cracks and crevices of hives under nest conditions. Few eggs were also noticed on the combs of weaker colonies. Oviposition occurred during night between 19.00 to $03.00 \mathrm{hr}$. During the development of the larva inside the egg, the prominent black head of the pre-emerged larva was observed inside the egg shell shortly before hatching. Egg Hatching was observed mainly during morning hours between 8-30 to 11.00 AM. The per cent hatch was almost 100 during summer months. Eggs measured $0.44 \pm 0.02$ $\mathrm{mm}$ long, $0.30 \pm 0.02 \mathrm{~mm}$ broad and the duration was $8.7 \pm 0.48$ days (Table 1 ). Elsawaf (1950) reported that the egg stage lasted for 9-10 days and Swamy (2007) reported egg stage lasted for 8.70 days the reasons for variation may be attributed to the possible differences in the ecological conditions that prevailed during the study period.

\section{Larva}

The newly hatched larva is pale whitish in colour. Immediately after hatching the young larva starts moving in search of food and starts feeding on the combs after perceiving the gustatory stimuli emanating from the bee combs. Larva burrow in to the outer edge of cell walls. After reaching the combs they generally move towards the mid rib of it. Developing larva extend their tunnels to the mid rib of the comb where they continue to feed. As the larva grows in size its colour changes to dirty grey. The growth rate of the larvae depends upon the temperature and the nature of food. The growth is quick on old or darker combs containing brood and pollen, but very slow and restricted upon white or fresh combs. The fast growth leads to the total destruction of the combs within a week of infestation. Wax moth larvae are capable of 
surviving even if food is available intermittently. Under such conditions the total development period greatly extends and the adults are correspondingly smaller. The larvae do not prefer processed wax and fresh or white combs. When the larvae was about to moult feeding cessations occurred and lost its colour cast off the exuvium of head capsule and rest of the body separately. Seven larval instars could be recognized in the present investigation as this also reported by Sehnal (1966), Anderson and Mignat (1970) and Swamy (2007).

The seven successive larval instars occupied $4.50 \pm 0.49,5.30 \pm 0.50,6.60 \pm 0.68,7.30 \pm 0.50$, $8.30 \pm 0.45,8.50 \pm 0.67$ and $9.30 \pm 0.40$ days. The total larval duration was $50.3 \pm 3.40$ days in the present investigation.

The larval period was reported from 39-62 days (Elsawaf, 1950), 22-27 days (Sehnal, 1966) and $49.3 \pm 1.62$ days Swamy (2007).
The variations could be attributed to the differences in the quality and quantity of food and also prevailing ecological conditions.

\section{Prepupa and cocoon}

Fully developed larvae when it enters in to seventh instar it will starts moving in search of suitable site for pupation and the larvae starts scrapes the surface slightly before pupation. The larvae entered crevices of the hive for pupation in apiary. The fully fed larva shrivels in size slightly and constructs the cocoon out of the silk and excreta by remaining inside. The cocoon is spindle shaped elongated, hard and leathery. The anterior part of cocoon was wider with an exit hole was closed by a thin layer of silken material and later pushed away at the time of moth emergence. The duration of prepupa was $2.20 \pm 0.53$ days. The mean length of the cocoon was $22.85 \pm 1.97 \mathrm{~mm}$, mean breadth of cocoon was $8.12 \pm 0.92 \mathrm{~mm}$ (Table 1$)$.

Table.1 Biology of greater wax moth Galleria mellonella on the combs of Apis cerana

\begin{tabular}{|l|l|l|l|l|l|}
\hline \multicolumn{1}{|c|}{ Life stages } & \multicolumn{1}{|c|}{$\begin{array}{c}\text { Duration } \\
\text { (days) } \\
\text { mean } \pm \text { sd }\end{array}$} & $\begin{array}{c}\text { Length(mm) } \\
\text { Mean } \pm \mathbf{s d}\end{array}$ & $\begin{array}{c}\text { Bredth (mm) } \\
\text { Mean } \pm \text { sd }\end{array}$ & $\begin{array}{c}\text { Head capsule } \\
\text { width(mm) } \\
\text { Mean } \pm \mathbf{s d}\end{array}$ & $\begin{array}{c}\text { Wing } \\
\text { expanse(mm) } \\
\text { Mean } \pm \mathbf{s d}\end{array}$ \\
\hline Egg & $8.70 \pm 0.48$ & $0.44 \pm \mathbf{0 . 0 2}$ & $0.30 \pm \mathbf{0 . 0 3}$ & - & - \\
\hline Larva & & & - & - & \\
\hline I instar & $4.50 \pm 0.49$ & $1.27 \pm \mathbf{0 . 4 7}$ & $0.25 \pm \mathbf{0 . 0 6}$ & $0.21 \pm \mathbf{0 . 0 7}$ & - \\
\hline II instar & $5.30 \pm 0.50$ & $2.40 \pm \mathbf{0 . 7 7}$ & $0.45 \pm \mathbf{0 . 0 6}$ & $0.33 \pm \mathbf{0 . 0 6}$ & - \\
\hline III instar & $6.60 \pm 0.68$ & $4.80 \pm \mathbf{0 . 6 4}$ & $1.26 \pm \mathbf{0 . 5 1}$ & $0.54 \pm \mathbf{0 . 0 5}$ & - \\
\hline IV instar & $7.30 \pm 0.50$ & $9.30 \pm \mathbf{0 . 7 0}$ & $1.56 \pm \mathbf{0 . 6 5}$ & $1.15 \pm \mathbf{0 . 4 3}$ & - \\
\hline V instar & $8.30 \pm 0.45$ & $15.50 \pm \mathbf{0 . 6 6}$ & $2.65 \pm \mathbf{0 . 6 6}$ & $1.28 \pm \mathbf{0 . 4 8}$ & - \\
\hline Vi instar & $8.50 \pm 0.67$ & $21.60 \pm \mathbf{0 . 6 4}$ & $3.30 \pm \mathbf{0 . 5 1}$ & $1.55 \pm \mathbf{0 . 4 2}$ & - \\
\hline VII instar & $9.30 \pm 0.40$ & $25.40 \pm \mathbf{1 . 1 9}$ & $4.86 \pm \mathbf{0 . 3 7}$ & $2.30 \pm \mathbf{0 . 5 0}$ & - \\
\hline Prepupa/Cocoon & $2.20 \pm 0.53$ & $22.85 \pm \mathbf{1 . 9 7}$ & $8.12 \pm \mathbf{0 . 9 2}$ & - & - \\
\hline Pupa & $8.65 \pm 0.73$ & $13.97 \pm \mathbf{0 . 5 9}$ & $4.30 \pm \mathbf{0 . 3 0}$ & - & - \\
\hline Adult male & $16.50 \pm 2.70$ & - & - & - & $24.60 \pm \mathbf{0 . 5 3}$ \\
\hline Adult female & $6.88 \pm 0.73$ & - & - & - & $25.20 \pm \mathbf{1 . 2 2}$ \\
\hline Pre-oviposition & $1.10 \pm 0.30$ & - & - & - & - \\
\hline Oviposition & $4.70 \pm 0.66$ & - & - & - & - \\
\hline Post-oviposition & $1.22 \pm 0.40$ & - & - & - & - \\
\hline FECUNDITY & & - & - & - & - \\
\hline Eggs/F & $760.90 \pm 168.88$ & - & - & - & - \\
\hline Eggs/F/day & $161.80 \pm 45.87$ & - & - & - & - \\
\hline
\end{tabular}




\section{Pupa}

The freshly formed pupa was obtect in shape, initially pale in colour and gradually reached dark brown towards end of maturity. A row of small spines were found just behind the head and extended to abdominal segment. The mean duration of the pupa was $8.65 \pm 0.73$ days. However, the pupal period was 6.5-8.00 days (Sehnal, 1966), 8-9 days (kannagara, 1940) and Swamy, (2007) 7-8.6 days.Some minor variations could be due to the change in climatic factors and the results were also in conformity with Swamy, 2007. The mean length and breadth of the pupae were $13.97 \pm 0.59$ and $4.30 \pm 0.30 \mathrm{~mm}$ respectively (Table 1).

\section{Adults}

Moth's emergence will occur only during night and late evening hours. The moths remained inactive till the wings were fully stretched and hardened. The moth is ash grey in colour and one third of each front wing being bronze coloured. The hind wing is uniformly grey coloured. The colour and size of the moth vary according to the food ingested during the larval period. Dark brown combs give rise to darker and bigger adults. The larvae fed on fresh combs, develop in to moths of lighter colour and smaller size. The antennae are filiform, longer then the head and thorax. The moths prefer dark places for hiding and very rarely they are attached to light.Adults were differ in their size, males are smaller than the females. The outer margin of the front wing of the males having a semilunar notch and the labial palpi are rudimentary, where as that of the female is smooth and without notch. The wing expanse of female was $25.20 \pm 1.22 \mathrm{~mm}$, where as in male, it was $24.60 \pm 0.53 \mathrm{~mm}$. Adult male lived for $16.50 \pm 2.70$ days and females lived for only 6.88 \pm 0.7 days (Table 1). Workers like (Elsawaf, 1950) observed adult longevity of 21-30 days for males and 8-15 days for females. This variation might be change in ecological factors and also the quality of food consumed in their larval stage and whereas Swamy (2007), reported the adult longevity 16.4 days for males and 6.90 days for females. The present study correlates with the findings of Swamy (2007).

\section{Biological Parameters of Females}

The moths begin to oviposit from one day after their emergence and continued it for a maximum period of one week. The moths oviposits during night time in groups. Preoviposition, Oviposition, Post-oviposition periods for females were $1.10 \pm 0.30$, $4.70 \pm 0.66$ and $1.22 \pm 0.40$ days, respectively. Females laid an average of $760.9 \pm 168.88$ eggs/female with $161.80 \pm 45.87$ eggs/female/ day (Table 2). These results were in agreement with Swamy (2007) he reported the wax moth female were an average of 760 eggs in their life span.

\section{References}

Adamson,A.M., 1943, Enemies and diseases of the honey bees in Trinidad. Proc.Agric.Soc.Trin.Tob., 43(1):37-39.

Anderson,M.A. and Mignat, E.C., 1970, The number of larval instars of greater wax moth (Galleria mellonella)with characters for identification of instars. $J$. Georgia Entomol. Soc., 5(2): 65-68.

El-sawaf, S.K., 1950, the life history of the greater wax moth (Galleria mellonella) in Egypt with special reference to the morphology of the mature larva (Lepidoptera: Pyralidae). Bull. Soc. Fouad. Ier. Ent. 34: 247-297.

Hanumanthaswamy, B C., 2000, Natural enemies of honey bees with special reference to bioecology and management of greater wax moth Galleria mellonella (Lepidoptera: 
Pyralidae) Ph.D Thesis, UAS bionomics and biometrics of the wax Bangalore, $257 \mathrm{Pp}$ moth (Galleria mellonella) reared under Hanumanthaswamy, B $\quad$ C., $2007 . \quad$ different conditions. J. Wiss. Zool., 174: BIONOMICS AND BIOMETRICS OF GREATER WAX MOTH (Galleria mellonellaL.) Asian J. Bio. Sci. (2007).Vol.3NO.1 (49-51)

Kapil, R.P. and Sihag, R.C., 1983, Wax moth and its control. Indian Bee J., 45: 47-49. 53-82.

Warren, L.O. and Huddleston, P., 1962, Life history of the greater wax moth (Galleria mellonella L). In Arkansas. $J$. Kans. Ent. Soc., 35: 212-216.

Sehnal, F., 1966, Critical study of the

\section{How to cite this article:}

Venkatesh Hosamani, B.C. Hanumantha Swamy, K.N. Kattimani and Kalibavi, C.M. 2017. 2017. Studies on Biology of Greater Wax Moth (Galleria mellonella L.). Int.J.Curr.Microbiol.App.Sci. 6(11): 3811-3815. doi: https://doi.org/10.20546/ijcmas.2017.611.447 